Athens a sober, bearded Aristotle encountered his master, a grinning cleanshaven Plato in the agora", or to take an actual example, "A short, round ebullient man Dunlap ....".

Perhaps the most interesting chapter is that on recent developments in applied psychology, many of which are valuable. It has, for example, been shown that people with their own office (known as "private space" in the jargon) both work more effectively and obtain greater job satisfaction than those in an open-plan space. Many large companies and most newspapers are either unaware of this finding or prefer to ignore it. A large cause of the Three Mile Island accident was that the displays had been designed by engineers not psychologists. Thirty per cent of them were too high for the operators to read, and the same colour coding was used to represent normal functioning on some displays and abnormal functioning on others. Companies, and even universities, continue to use the interview as a method of selection, despite the fact that it is useless if more objective data are available. Although good applied psychology can be extremely helpful, there is a debit side. Don't believe anyone who claims that biofeedback works, that you can learn in your sleep, that subliminal stimuli can influence motivation, or that halfbaked seminars given by a so-called psychologist can improve creativity or productivity in a company. All such techniques, however plausible, have to be validated before they can be known to be of use. If you want to know whether the introduction of any change is helpful, only the psychologist is equipped to find out. It sounds easy, but it is no mean feat. Surprisingly, Hunt fails to point out the most important achievement of 3,000 years of psychology, namely, the development of good experimental techniques. Nowadays, psychology's methodology is even influencing other disciplines, such as medicine and biology, thus repaying some of the debt owed.

Stuart Sutherland is in the Department of Experimental Psychology, University of Sussex, Brighton BN1 9QG, UK.

\section{New in paperback}

Niels Bohr's Times, in Physics, Philosophy, and Polity by Abraham Pais, Oxford University Press, $£ 12.95, \$ 17.95$. For a review see Nature 353, 511 (1991). The New Turing Omnibus: 66 Excursions in Computer Science by A. K. Dewdney, Freeman, $£ 19.95$. $\$ 24.95$. For a review see Nature 341, 496 (1989).

\title{
Just the facts
}

Manfred Schliwa

The Adhesion Molecule FactsBook. By Rod Pigott and Christine Power. Academic Press: 1993. Pp. 190. £19.50, \$42.

Guidebook to the Cytoskeletal and Motor Proteins. Edited by Thomas Kreis and Ronald Vale. Oxford University Press: 1993. Pp. 276. £22.50, \$37 (pbk); £45, $\$ 75$ (hbk).

Guidebook to the Extracellular Matrix and Adhesion Proteins. Edited by Thomas Kreis and Ronald Vale. Oxford University Press: 1993. Pp. 176. £18.50, $\$ 30$ (pbk); $£ 40, \$ 65$ (hbk).

PICTURE this: you are attending a meeting on structural proteins. In the discussion after one of the talks the speaker reassures a discussant that 'his' protein has features reminiscent of $\mathrm{ABC} 123^{\mathrm{xyz}}$, a component of periparaprosynfitin. You are alarmed did you miss something important there? $\mathrm{ABC} 123^{\mathrm{xyz}}$ sounds vaguely familiar, but what is its relationship to periparaprosynfitin (or was it ... synphitin?). You decide to start a computer search once you return to your laboratory and wish for a ready source that would refresh your memory on these proteins.

Now a remedy is here - at least as far as cytoskeletal, adhesion and extracellular matrix proteins are concerned. These books provide concise descriptions of most of the proteins that make up these three classes of structural proteins. Between 1 and 5 pages are devoted to a terse characterization of the essential features of each protein. Indeed, 'essential' is the spiritus rector of these publications. Descriptions of molecules dominate; function in a cellular context is only touched upon or is left to the introductory chapters. These are the kinds of books where one would expect to be able to read up, in 5-10 minutes, on $\mathrm{ABC} 123^{\mathrm{xyz}}$ (if it existed) and its interaction with periparaprosynfitin (sic). The style of presentation is similar in the two types of publications. The FactsBook provides a more rigid framework for the delivery of the facts and includes amino-acid sequences and wherever possible, a diagram of the domain structure of each protein discussed. The Guidebooks rarely present sequence information but frequently include original micrographs of the molecules and their distribution in the cell. A combination of both these features may seem desirable for future editions.

These are no books for beginners, but they will be welcomed by those new to these fields and, I dare say, virtually everyone already working in them. Not many of us are able to keep a mental record of the features of all the cytoskeletal/adhesion/matrix proteins and their aliases (for example, CD44 = H$\mathrm{CAM}=\mathrm{G} 90^{\mathrm{HERMES}}=\mathrm{Pgp}-1=\mathrm{ECMR}$ $\mathrm{III}=\mathrm{In}(\mathrm{lu})$-related p $80=\mathrm{HUTCH}-1=$ $\mathrm{LY}-24=\mathrm{p} 85$ ). New proteins and isoforms are being discovered, sequenced and characterized at an astonishing rate, and therefore publications of an encyclopaedic nature are becoming increasingly popular and useful. Of course they will not replace textbooks, monographs or proceedings, but they will supplement them.

This is a new type of publication for the cell biology field, and naturally there are some problems to be overcome. A major difficulty recognized by the authors/ editors is that there are no rigorous, uniform criteria for the selection of entries. Pigott and Power suggest such a criterion for adhesive molecules (expression in a cell confers an adhesive phenotype that can be inhibited by specific antibodies) but also realize that this criterion is met by only a minority of proteins presumed to be adhesive. Kreis and Vale intended to include only the well characterized structural proteins that had been purified, sequenced and had antibodies raised against them, but several of their entries do not fulfil these criteria.

A second, related problem concerns the uniform weighting of entries: proteins such as actin, tubulin, tropomyosin or MAP2 on which hundreds or thousands of papers have been published are allowed just as much space as, for example, tenuin, on which one publication (without sequence) is available, or pericentrin, for which no full paper has yet been published. Perhaps some of the new, more exotic fruits should be given more time to ripen before they are served to a wider audience.

A last concern is timeliness. Compilations of an encyclopaedic nature such as these will remain valuable only if updated. New information is accumulating rapidly. For example, the entire myosin section of the Guidebook may require a revision soon to include a discussion of the many new members of this rapidly growing protein family. The inside front cover of the Guidebook announces a computer database, for updates only, of the entries in the Guidebook which authors of papers are requested to provide. This is laudable, but it may be dangerous to leave the entry of updates to the discretion and/or leisure of the authors. The hardware (books) should be updated, too, perhaps by converting them to loose-leaf editions where updates replace older entries and new proteins can be added. For these publications are bound to remain in demand and are likely to become even more effective and valuable in the future.

Manfred Schliwa is at the Institute for Cell Biology, University of Munich, Schillerstrasse 42, 80336 Munich, Germany. 